\title{
Molecular Cloning and Structure-Function Analysis of a Trypsin Inhibitor from Tartary Buckwheat and Its Application in Combating Phytopathogenic Fungi
}

\author{
Jing-jun Ruan ${ }^{1}{ }^{(D}$, Shan-jun Tian ${ }^{1}$, Jun Yan ${ }^{2,3}$, Hui Chen ${ }^{4}$, Ru-hong $X u^{1}$ \\ and Jian-ping Cheng ${ }^{1, *}$ \\ 1 College of Agriculture, Guizhou University, Guiyang 550025, China; \\ chenggy508@sohu.com (J.-j.R.); jjruan@gzu.edu.cn (S.-j.T.); rhxu@gzu.edu.cn (R.-h.X.) \\ 2 Institute of Evolution, University of Haifa, Haifa 31905, Israel; jyan@cdu.edu.cn \\ 3 School of Pharmacy and Bioengineering, Chengdu University, Chengdu 610106, China \\ 4 College of Life Science, Sichuan Agriculture University, Ya'an 625014, China; hchen@sicau.edu.cn \\ * Correspondence: ruanj741@aliyun.com; Tel.: +86-0851-83855894
}

Received: 10 January 2018; Accepted: 10 April 2018; Published: 12 April 2018

\begin{abstract}
Host plant protease inhibitors offer resistance to proteases from invading pathogens. Trypsin inhibitors (TIs), in particular, serve as protective agents against insect and pathogen attacks. In this study, we designed a pair of degenerate primers based on highly conserved motifs at the Nand C-termini of the TI from tartary buckwheat (Fagopyrum tataricum; Ft) to clone the central portion. Genomic walking was performed to isolate the $5^{\prime}$ and $3^{\prime}$ flanking regions of FtTI. We demonstrated the successful PCR amplification of a $644 \mathrm{bp}$ portion of FtTI. The full-length DNA of FtTI contains a complete open reading frame of $264 \mathrm{bp}$, encoding 87 amino acids with a mass of approximately $9.5 \mathrm{kDa}$. The FtTI protein sequence was $49 \%$ identical and $67 \%$ similar to potato protease inhibitors. Site-directed mutagenesis identified the residues, $\mathrm{Asp}^{67}$ and $\mathrm{Arg}^{68}$, as crucial for the inhibitory activity of the FtTI. Recombinant and mutant FtTI inhibited both the hyphal growth and spore germination of Alternaria solani. The calculated 50\% inhibitory concentrations of FtTI ranged from 5-100 $\mu \mathrm{g} \mathrm{mL}^{-1}$ for spore germination and $1-50 \mu \mathrm{g} \mathrm{mL}^{-1}$ for fungal growth. Thus, recombinant FtTI may function in host resistance against a variety of fungal plant pathogens.
\end{abstract}

Keywords: tartary buckwheat; trypsin inhibitor; genome walking; phytopathogenic fungi

\section{Introduction}

Fungal pathogens have a major influence on agricultural crop yields and are a very serious threat to global food security. Traditional measures of disease control rely heavily on chemical methods which have allowed farmers to overcome many common plant diseases [1]. Early blight of tomato caused by Alternaria solani is an important fungal disease worldwide. The most used and effective control method is the application of synthetic chemical fungicides. However, they are generally used in excess, causing environmental contamination and human health problems, and can even lead to the emergence of pathogen-resistant strains [2]. Therefore, alternative products, such as natural products from plant extracts, should be developed to reduce the dependence on synthetic chemical fungicides. Exposure to severe environments and evolution have allowed plants to develop efficient protective mechanisms against phytopathogens. Among these, plant proteins exhibiting toxic or antimetabolic activities toward pathogens are of great interest. The roles played by antifungal proteins in plant defense have been well studied [1]. These proteins, such as protease inhibitors, can provide an obstacle during the early stages of infection. Protease inhibitors are also considered protective 
proteins because they suppress the activity of proteolytic enzymes of both pathogenic microorganisms and herbivorous pests that try to penetrate the host plant tissues [3]. There is growing interest in the use of plant protease inhibitors for the protection of agricultural crops, owing to their low toxicity to mammals and low persistence in the environment. Protease inhibitors that suppress the activity of specific proteases are present in animals, plants, and microorganisms $[4,5]$. The best studied are the serine protease inhibitors. These have been found in many plant species in which they participate in the defense against phytophagous insects and microorganisms. Plant protease inhibitors have been isolated and characterized from Leguminosae, Solanaceae, Gramineae, and Cruciferae [6-8]. In their defense against natural enemies, plants have formed a variety of protease inhibitors, the best-characterized being members of four different families: the Kunitz-type (18-22 kDa), the Bowman-Birk (8-10 kDa), the Kazal (6-8 kDa), and potato protease inhibitor I (10-14 kDa) [9]. In these four families, the reactive P1 residue is always an arginine or lysine $[9,10]$. The active sites of plant protease inhibitors result from their capacities to form stable complexes with microbial secreted proteases; these complexes then block, alter, or prevent access to the microbial proteolytic enzymes' active sites.

To clone an unknown target gene, it is often necessary to perform a multiple sequence alignment that includes the amino acid sequence of the known protein. Successful cloning usually relies on the identification of clear blocks of conserved regions in multiple global alignments [11]. Therefore, the alignment quality must be high. However, in many cases, degenerate primers designed using multiple sequence alignments are unsuccessful, owing to the poor conservation among the amino acid sequences being studied. To overcome this problem, Boyce et al. suggested a method of designing degenerate primers that can be used for sequencing without well-conserved blocks in multiple sequence alignments [12]. The technique is based on multiple sequence alignments using the consensus degenerate hybrid oligonucleotide primers (CODEHOPs) to identify conserved regions that are long enough to serve as primers $[12,13]$. The $3^{\prime}$-degenerative structure of consensus degenerate hybrid oligonucleotide primers allows a wide PCR specificity for remotely relevant goal gene templates, while the $5^{\prime}$-consensus clamp permits the strong amplification from PCR product templates during the later PCR amplification cycles. The CODEHOP method has been applied to characterize novel genes and distinguish unknown plant protease inhibitors. It has been particularly useful for remotely relevant targets and with a finite template in complicated mixtures. Three rounds of successive PCR amplifications by locus-specific and walker primers and their corresponding nested primers can effectively amplify flanking DNA fragments [14]. Only the correct degenerate primers are designed to ensure that a certain percentage of primers can be paired with the template correctly [15]. Simultaneous high-throughput three-step PCR-based genome walking, followed by direct sequencing of PCR-amplified fragments with specific nested sequencing primers may enable the development of new research strategies for gap closure in genome-assembly projects [16]. The rapid PCR-based DNA walking can be performed with any plant genomic DNA to walk directionally from any sequence-tagged site. It is a rapid and reliable way of randomly introducing unique walker primer-binding sites into different regions of the genome by annealing long synthetic oligonucleotides with partial degeneracy at the $3^{\prime}$ or $5^{\prime}$ end, for proper annealing and then extending with DNA polymerase.

Buckwheat is divided into two major species with agricultural significance, common (Fagopyrum esculentum Moench) and tartary (Fagopyrum tataricum Gaertn) buckwheat [17]. Tartary buckwheat is widely cultivated in the southwestern mountains of China and grows mainly on the Yunnan-Guizhou Plateau (altitude range: 2100-3400 m above sea level). Common buckwheat protease inhibitors have remarkable functions and anti-inflammatory, anti-leukemia, anticancer, anti-bollworm, and anti-plant fungal disease effects [18-23]. However, there are relatively few studies on tartary buckwheat protease inhibitors. In recent years, we have isolated and purified a trypsin inhibitor (TI) of tartary buckwheat (FtTI) in vitro [24], and have cloned and expressed the corresponding gene in Pichia pastoris [25]. However, we do not know the structure of the promoter sequence or if it has an intron sequence. Moreover, the expression level of FtTI in P. pastoris is relatively low; therefore, we wished to clone FtTI and express it in Escherichia coli for tomato fungal defense. The protease inhibitor active site's 
amino acid residues play critical roles in their inhibitory functions, and if a mutation occurs in the site, it loses nearly $100 \%$ of its inhibitory activity. An arginine or lysine residue must be present in the P1 subsite for trypsin inhibition [10]. To reveal the molecular mechanism associated with the inhibitory effect of FtTI toward animal proteases and proteases present in plant-pathogenic microorganisms, the nucleotide sequences of 86 protein residues and three mutants of FtTI were artificially synthesized by PCR amplification and independently expressed by fusion in E. coli DE3. The recombinant protein was purified by one-step affinity chromatography and its activity against plant-pathogenic fungi was evaluated.

\section{Materials and Methods}

\subsection{Experimental Materials}

The Genome Walking Kit, restriction endonucleases, TaKaRa Mutant BEST Kit and T4 DNA ligase were purchased from TaKaRa (Shiga, Japan). E. coli DH5a obtained from Novagen was used for cloning and nucleotide sequencing. E. coli BL21 and vector pET-32a were obtained from Invitrogen. The T-A cloning vector $\mathrm{pMD} 19-\mathrm{T}$ was obtained from TaKaRa, and was used to construct recombinant plasmids for subcloning and sequencing.

\subsection{Cloning of the FtTI Gene}

\subsubsection{Nucleic Acid Preparation}

DNA and RNA were isolated from tartary buckwheat using the MiniBEST Universal Genomic DNA Extraction Kit and the RNAiso plus Total RNA Extraction Kit (TaKaRa), respectively, unless otherwise stated. DNA and RNA concentration and purity were determined by measuring optical density at 260 and $280 \mathrm{~nm}$ using a spectrophotometer (SHIMADZU Uvmini-1240, Kyoto, Japan). RNase and DNase were added during the extraction procedure for DNA and RNA, respectively, and negative controls were run with each. First-strand cDNA was synthesized using Reverse Transcriptase M-MLV (TaKaRa) and oligo (dT) priming on DNase-treated RNA.

\subsection{2. cDNA Cloning of the Central Fragment of FtTI}

Degenerate PCR primers (Table 1) were designed to amplify an internal fragment of FtTI based on the conserved regions of several protein sequences of known protease inhibitors obtained from the NCBI Protein Sequence Database. Multiple alignments of amino acid sequences were performed with CLUSTAL-W2 software, and highly conserved amino acid motifs were compared.

Table 1. Primers used in this study.

\begin{tabular}{|c|c|c|}
\hline Primer Name & Primer Sequence $\left(5^{\prime} \rightarrow 3^{\prime}\right)$ & Purpose \\
\hline CAAP1 & TGG CCN GAR CTN GTT GGA & Conservative area DNA \\
\hline CAAP2 & RAC NCA YAC NCG GTC ACA & Conservative area DNA \\
\hline SP1 & TCA CAA CGA AAG TCG AAA GTG C & 5' Genome walking \\
\hline SP2 & GGT GGC TAG AGT GGT TAA AGG AGG & $5^{\prime}$ Genome walking \\
\hline SP3 & CTT CCC TTT GGT TCC AAC AAG C & $5^{\prime}$ Genome walking \\
\hline SP4 & ACC CGG TCA CAA CGA AAG TC & $3^{\prime}$ Genome walking \\
\hline SP5 & CAC AAC GAA AGT CGA AAG GTC & 3' Genome walking \\
\hline SP6 & GTG CGG CAG GTG GCT AGA GT & 3' Genome walking \\
\hline Fusion expression P1 & CCG GAA TTC CAT GTT AAT TTA CGC TAA AGT T & Fusion expression of gene \\
\hline Fusion expression P2 & GAA TGC GGC CGC ACC GAC GGT TGG GGT & Fusion expression of gene \\
\hline SMP1 & CGT TGT GAC CTG GTG CGT GTT TTA A & Site mutation, R68L \\
\hline SMP2 & AAA GTG CGG CAG GTG GCT AGA GTG G & Site mutation, R68L \\
\hline SMP3 & CTT TCG TTG TGT CCG GGT GCG TGT T & Site mutation, D67V \\
\hline SMP4 & TCG AAA GTG CGG CAG GTG GCT AGA G & Site mutation, D67V \\
\hline SMP5 & CTT TCG TTG TGT CCT GGT GCG TGT T & Site mutation, D67V, R68L \\
\hline SMP6 & TCG AAA GTG CGG CAG GTG GCT AGA G & Site mutation, D67V, R68L \\
\hline
\end{tabular}




\subsubsection{Genome Walking}

The $5^{\prime}$ and $3^{\prime}$ flanking regions of FtTI were isolated with the Genome Walking Kit (TaKaRa) according to the manufacturer's instructions. Primary and nested PCRs were performed with forward primers complementary to the adaptor sequence (adaptor primers (AP) 1, 2, and 3 provided with the kit), and FtTI gene-specific primers (GSPs) 1, 2, and 3, corresponding to residues 20-43, 67-90, and 110-133, respectively, which were designed based on the cDNA-cloned central fragment of FtTI.

\subsection{Site-Directed Mutagenesis}

Site-directed mutagenesis and sequence assays were carried out as described previously [26-28]. FtTI genes with point mutations were independently introduced into the cloning vector pMD19-T by PCR. The forward and reverse oligonucleotide primers (Table 1) were complementary to the opposite strands of the vector and contained the desired mutations in the middle of the primers. Extensions with these primers generated mutated plasmids at the relevant sites. Each PCR had a total volume of $50 \mu \mathrm{L}$, containing $5.0 \mu \mathrm{L}$ of $10 \times$ Pyrobest Buffer II, $4.0 \mu \mathrm{L}$ of $2.5 \mathrm{mM}$ dNTP mixture, $1.0 \mu \mathrm{L}$ of each primer $(20 \mu \mathrm{M}), 0.25 \mu \mathrm{L}$ of Pyrobest DNA polymerase and $0.5 \mathrm{ng}$ of pMD19-FtTI plasmid DNA. Sterilized distilled water was added to $50 \mu \mathrm{L}$. The reaction scheme was as follows: one cycle of initial denaturation $\left(95^{\circ} \mathrm{C}\right.$ for $4 \mathrm{~min}$ ), 30 cycles of amplification with a lower annealing temperature $\left(94{ }^{\circ} \mathrm{C}\right.$ for $30 \mathrm{~s}, 56{ }^{\circ} \mathrm{C}$ for $45 \mathrm{~s}$, and $72{ }^{\circ} \mathrm{C}$ for $5 \mathrm{~min}$ ), and cooling to $4{ }^{\circ} \mathrm{C}$. The PCR products were subjected to a blunting reaction, in which the PCR had a total volume of $50 \mu \mathrm{L}$, containing 1 pmol DNA fragment,

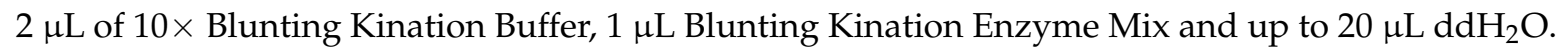
The PCR program was as follows: $37^{\circ} \mathrm{C}$ for $10 \mathrm{~min}$ and then $70{ }^{\circ} \mathrm{C}$ for $10 \mathrm{~min}$. Approximately $0.25 \mathrm{mmol}(5 \mu \mathrm{L})$ of this solution was added to a microcentrifuge tube in which the ligation reaction was carried out. Ligation Solution I $(5 \mu \mathrm{L})$ was added and mixed well. The reaction solution was completely transformed into $100 \mu \mathrm{L}$ competent cells. The reaction was carried out for $1 \mathrm{~h}$ at $16^{\circ} \mathrm{C}$. All constructs were confirmed by direct DNA sequencing.

\subsection{Expression of FtTI and FtTI Mutants in E. coli}

No start and stop codon regions of FtTI and the FtTI mutants, which were independently inserted into the E. coli expression vector pET32a (Novagen), were amplified by PCR. The pET-32 series was designed for the cloning and high-level expression of peptide sequences fused with the 109 amino acid Trx.Tag ${ }^{\mathrm{TM}}$ thioredoxin protein. The expression vectors were independently introduced into E. coli BL21 Star (DE 3) cells, and gene expression was induced by the addition of $0.5 \mathrm{mM}$ isopropyl $\beta$-D-1-thiogalactopyranoside when the culture reached an optical density of 0.65 at $600 \mathrm{~nm}$. After induction and growth overnight at $30^{\circ} \mathrm{C}$, the cells expressing FtTI and its mutants were centrifuged at $4000 \times g$ for $15 \mathrm{~min}$, and $1 \mathrm{~mL}$ aliquots of the spent medium were placed in individual vials for further analyses.

\subsection{Affinity Purification of FtTI and FtTI Mutants}

His-tagged FtTI and FtTI mutants were individually affinity-purified by nickel-agarose chromatography using a protocol described previously [9]. After elution from the nickel-agarose column, the proteins were dialyzed against $50 \mathrm{mM}$ phosphate buffer $\mathrm{pH} 6.8,500 \mathrm{mM} \mathrm{NaCl}, 1 \mathrm{M}$ $\left(\mathrm{NH}_{4}\right)_{2} \mathrm{SO}_{4}, 2 \mathrm{mM}$ dithiothreitol. To evaluate purity, dialyzed fractions of purified protein were subjected to SDS-PAGE followed by Coomassie Brilliant Blue staining [22].

\subsection{Molecular Weight Determination and Western Blot Analysis}

The purified recombinant protein was subjected to SDS-PAGE using a $12.5 \%$ and $4 \%$ polyacrylamide slab gel system as described by Laemmli [29], and then transferred to a polyvinylidene fluoride membrane (Millipore, Burlington, MA, USA) using $100 \mathrm{mM} \mathrm{N}$-cyclohexyl-3-aminopropanesulfonicacid buffer, $\mathrm{pH}$ 11, at $100 \mathrm{~V}$ for $30 \mathrm{~min}$ [30]. After blocking with skim milk, the membrane was rinsed twice 
for 5 min with $25 \mathrm{~mL}$ Tris buffered saline-Tween (TBS-T). The blot was placed in a box containing $3 \mathrm{~mL}$ mouse anti-histidine for $1 \mathrm{~h}$. The membrane was rinsed three times for $5 \mathrm{~min}$ in TBS-T and then moved to a sealed box with $3 \mathrm{~mL}$ goat anti-mouse alkaline phosphatase-conjugated IgG for $1 \mathrm{~h}$. After incubation, the membrane was rinsed four times with $25 \mathrm{~mL}$ TBS-T. Then, the membrane was soaked in $25 \mathrm{~mL}$ alkaline phosphatase buffer for $2 \mathrm{~min}$. After washing away the buffer, $5 \mathrm{~mL}$ color substrate solution with $50 \mu \mathrm{L}$ 5-bromo-4-chloro-3-indolyl phosphate and $50 \mu \mathrm{L}$ tetranitroblue tetrazolium chloride was applied. The color reaction was allowed to proceed in the dark for approximately $20 \mathrm{~min}$.

\subsection{Determination of Recombinant FtTI Inhibitory Activity}

Trypsin inhibitory activity on bovine pancreatic and tomato early blight trypsins were determined by the method of [8]. Different concentrations of TI were incubated with $5.6 \times 10^{-7} \mathrm{M}$ trypsin (final concentration in $1.5 \mathrm{~mL}$ assay volume) for $15 \mathrm{~min}$ at $30^{\circ} \mathrm{C}$ in $67 \mathrm{mM} \mathrm{K} / \mathrm{Na}$-phosphate buffer, pH 6.8 . After $15 \mathrm{~min}$ incubation, $1.0 \mathrm{~mL}$ of $0.5 \mathrm{mM} \mathrm{N}$-benzoyl-DL-arginine- $p$-nitroaniline hydrochloride was added. After incubation for another $15 \mathrm{~min}$ at $30^{\circ} \mathrm{C}$, the reaction was stopped by adding $200 \mu \mathrm{L}$ of $10 \%$ acetic acid. The changes in absorbance at $410 \mathrm{~nm}$ were recorded at $30{ }^{\circ} \mathrm{C}$ against a blank solution containing $1.5 \mathrm{~mL}$ of the substrate solution in the same buffer with a Shimadzu UV mini- 1240 spectrophotometer. One unit of inhibitor activity produced a 0.1 unit decrease in absorption of the solution in the trypsin activity assay. The inhibition constants (Kis) for trypsin were measured using a Dixon plot ( $1 / \mathrm{V}_{0}$ against inhibitor), with two different substrate concentrations, 0.01 and $0.005 \mathrm{mo} \mathrm{L}^{-1}$ for $N$ - $\alpha$-benzoyl-L-arginine ethyl ester hydrochloride.

\subsection{Bioassay of Inhibition of Spore Germination and Hyphal Growth by Recombinant FtTI}

Spore suspensions of $A$. solani were shaken vigorously for $2 \mathrm{~min}$. A $0.1 \mathrm{~mL}$ aliquot of the suspension was dispensed into a microtube containing potato dextrose broth (Difco; $0.4 \mathrm{~mL}, 0.5 \%$ ), and the recombinant FtTI protein was added [31]. After incubating A. solani spores for $6 \mathrm{~h}$ at $28^{\circ} \mathrm{C}$, germinated spores were counted using a hemocytometer and light microscope. Conidial suspensions of $A$. solani in potato dextrose broth were incubated in microtubes until the hyphae had an average length of $25 \mathrm{~mm}$. A $0.1 \mathrm{~mL}$ sample of the recombinant FtTI protein was then added to the conidial suspension. Various concentrations of the recombinant FtTI protein were used. The mixture was incubated at $30^{\circ} \mathrm{C}$ until the control germlings attained an average length of approximately $300 \mathrm{~mm}$. The lengths of 50 individual hyphae were determined using a Nikon UFX-DX light microscope (Nikon, Tokyo, Japan). Hyphal lengths and conidial germination were determined, for each replicate, from at least ten randomly chosen germ tubes and 50 conidia, respectively.

\subsection{Experimental Design and Statistical Analysis}

All data are expressed as means \pm standard deviations (SDs) of three replications, and an Analysis of Variance (ANOVA) (SAS Inst. Inc., Cary, NC, USA) was carried out for the statistical analysis. The values were considered significantly or highly significantly different at $p<0.05$ and 0.01 , respectively [32].

\section{Results and Discussion}

\subsection{Cloning and Characterization of FtTI}

PCR was used to amplify the conserved $147 \mathrm{bp}$ fragment of FtTI that encoded 49 amino acids. A nucleic acid sequence alignment analysis showed no homology with the protease inhibitor genes of other higher flora and fauna, but this fragment showed a $42.8 \%$ homology with the Xenopus (Silurana) tropicalis (NM_001114247.1) interleukin gene. The 49 amino acid sequence alignment analyses showed there is a $47-59 \%$ homology with the protease inhibitor-like proteins of other higher plants. The fragment was thought to be a new protease inhibitor. Genome walking was used to propagate the full-length DNA of FtTI. The gDNA sequence of the full-length FtTI was $644 \mathrm{bp}$. 
A DNAStar software analysis showed an open reading frame between nt 207 and 472, encoding 87 amino acids. The $5^{\prime}$ untranslated region was $207 \mathrm{bp}$ in length, and the upstream sequence had two control elements and was GC rich. There was a conserved TATATT box upstream of the promoter at nt -25 to -35 , and the start codon (ATG) was located at nt 209-211; the initial codon region sequence ATAATGT is a typical conserved region of the plant gene, with -3 bp being $A / T$, and +4 being $T$. The stop codon (TGA) was located at nt 469-471; the stop codon to the poly (A) tail for the noncoding region, in total $176 \mathrm{bp}$, was AT rich, including a typical AATAAA hex nucleotide polyadenylation signal sequence (Figure 1). There are no introns in the FtTI full-length sequence. Therefore, the coding sequence of the FtTI gDNA can be directly expressed in prokaryotic cells. A BLAST algorithm-based sequence homology analysis in GenBank showed that the gene's sequence was completely different from that of the plant protease inhibitor gene, and was a new gene in dicotyledonous plants. Where the inhibitor background is not understood, and no homologous sequence can be used for reference, primer design is difficult. In this study, the biggest difficulty in primer design was that the amino acids in the conserved region of the inhibitor protein sequence were mostly encoded by a highly degenerate codon, which is very unfavorable to the specificity of PCR amplification. Using the primary structure of the FiTI and the conserved amino acid sequences of protease inhibitors from common buckwheat and other plant species, WPELVG and CDRVW, with high homology levels, were found at the Nand C-termini. A partially degenerate codon was applied to clone its conserved region's sequence, and then genome walking was used to clone the full length of the FiTI gene for the first time.

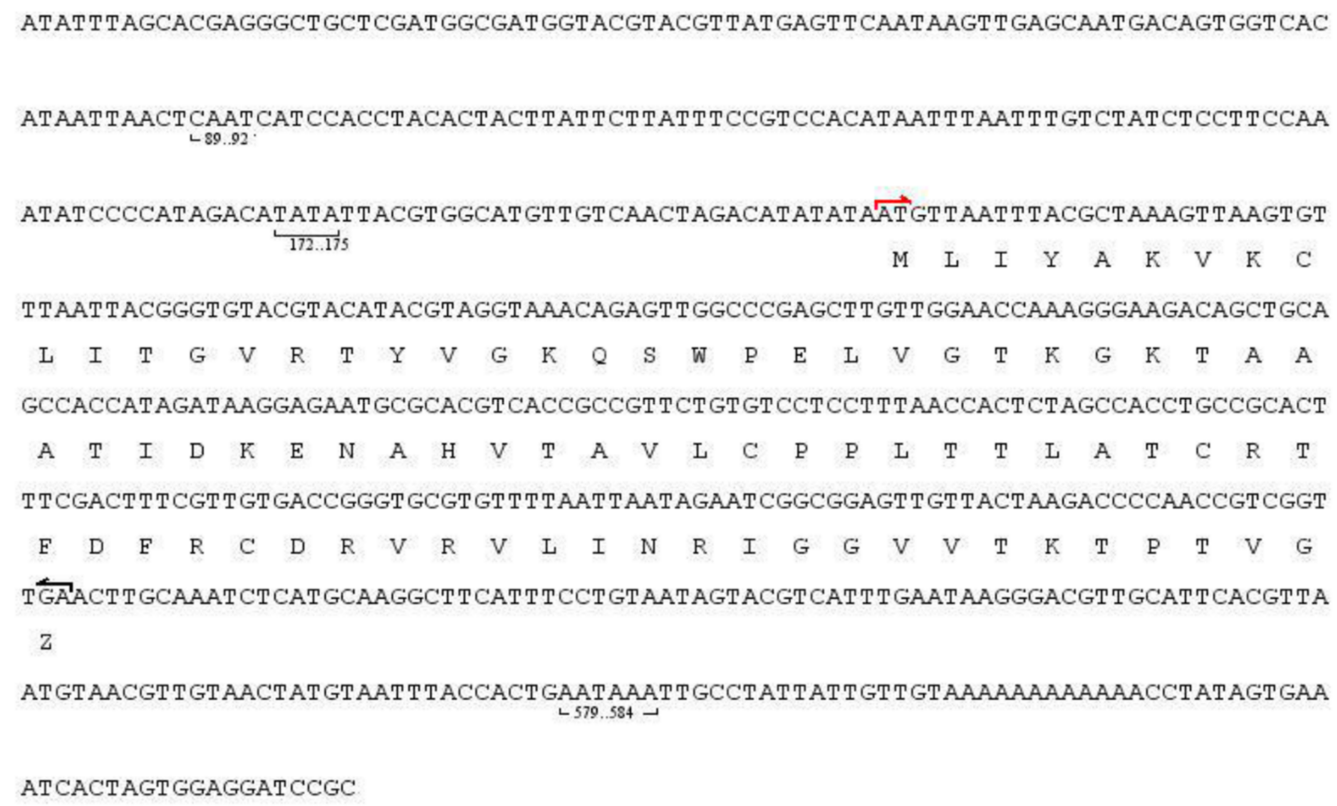

Figure 1. Nucleotide sequences of FtTI. The open reading frame, from bases 208 to 471 predicts an 87 amino acid sequence before a stop signal $(Z)$ is encountered. The promoter sequences, CAAT and TATA, in the $5^{\prime}$-untranslated region are from 89 to 92 and from 172 to 175, respectively. The poly (A) signal, AATAAA, in the $3^{\prime}$-untranslated region is from 579 to 584 .

\subsection{Expression and Purification of FtTI and FtTI Mutants}

The major objective of this study was to determine whether the FtTI P1 loop is indeed the reactive site responsible for inhibiting trypsin and, in particular, whether Asp ${ }^{67}$ and Arg ${ }^{68}$ are involved in this inhibition. Three FtTI mutants of conserved active site amino acids and FtTI were independently produced in E. coli strain BL21 (DE3), an expression host designed for enhanced yields of active soluble recombinant proteins. The three mutants and recombinant FtTI were expressed in a pET-32a (+) vector, and the recombinant products, fused with His tags, were isolated, purified, and their inhibitory activity 
levels measured. An SDS-PAGE analysis of the expressed product showed similar molecular weights for FtTI before and after the mutations, $9.5 \mathrm{kDa}$ (Figure 2). Using E. coli BL21 (DE3) cells for expression, the yields of purified proteins recovered exclusively from the intracellular soluble fraction were 256 $\mathrm{mg}$ (D67V), $264 \mathrm{mg}$ (R68L), $248 \mathrm{mg}$ (R68L/D67V), and $287 \mathrm{mg}$ (recombinant FtTI) per $1 \mathrm{~L}$ of culture. These expression levels are very similar to those reported for other recombinant plant protease inhibitors, such as mustard, mung bean and winged bean TIs, with yields of approximately 180-200 mg per $1 \mathrm{~L}$ of culture $[4,5,26]$. E. coli BL21 (DE3) cells were induced for $5 \mathrm{~h}$ with isopropyl $\beta$-D-thiogalactoside.

A

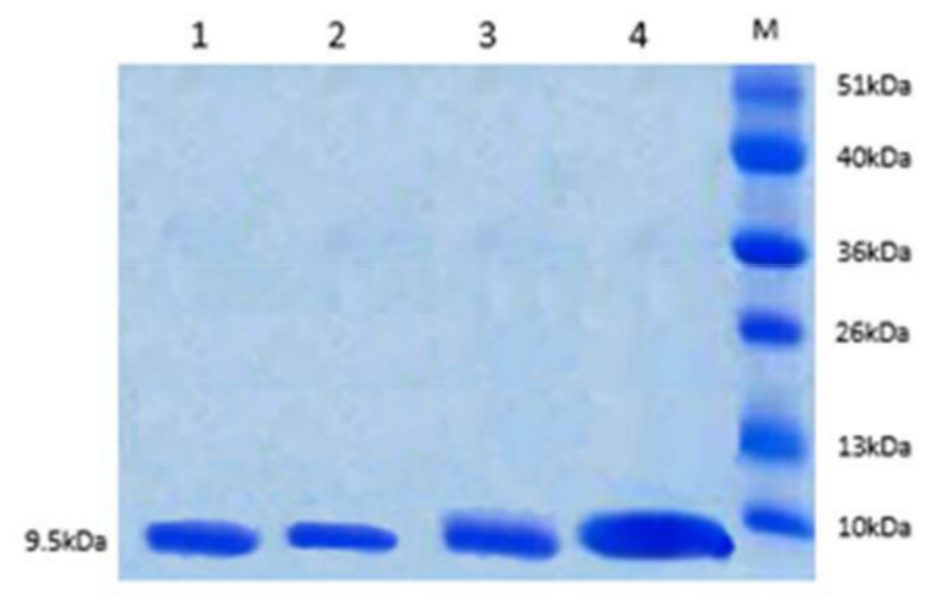

B

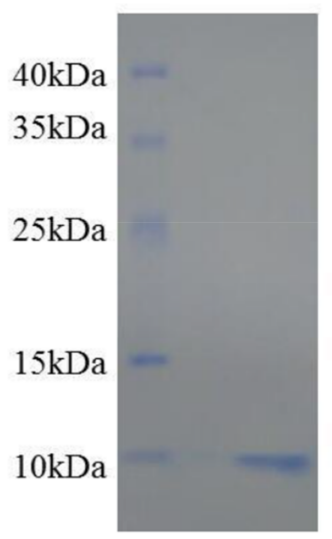

Figure 2. SDS-PAGE (A) and Western blot analysis (B) of recombinant FtTI and its mutants. (A) Lanes 1, 2, 3, 4, and M: recombinant FtTI mutants R65L, D67V, and R65L/D67V, recombinant FtTI, and molecular mass standards, respectively; (B) Western blot analysis of the purified recombinant protein.

\subsection{Analyses of the Characteristics of Recombinant FtTI and Its Mutants}

It has been reported that $\mathrm{Asp}^{67}$ and $\mathrm{Arg}^{68}$ are P1 residues of the potato protease inhibitor I family's active site [10]. Data obtained from a multiple alignment study of FtTI with a number of other similar TIs showed that the Arg or Asp residue of FtTI remained conserved among the proteins [24]. As shown in Table 1, we selected $\mathrm{Asp}^{67}$ and $\mathrm{Arg}^{68}$ for mutation to address two questions: (i) whether the positively charged $\left(\mathrm{Arg}^{68}\right)$ or negatively charged $\left(\mathrm{Asp}^{67}\right) \mathrm{N}$-terminal residue plays a role in stabilizing the inhibitory active site; and (ii) whether the simultaneous mutation of these two amino acids will lead to a more severe decline in inhibitory activity. FtTI was mutated by site-directed mutagenesis technology, and three mutant strains, D67V, R68L, and R68L/D67V, were obtained. The recombinant and mutated FtTI peptides had no inhibitory activity against chymotrypsin. The inhibition kinetics of the mutants D67V, R68L, and R68L/D67V, as well as the recombinant FtTI peptide for bovine trypsin and chymotrypsin, were assessed by determining the equilibrium dissociation constant $K_{i}$ values using the Dixon plot. The $K_{i}$ values for bovine trypsin were, respectively, $3.3 \times 10^{-8} \mathrm{mo} \mathrm{L}^{-1}, 1.9 \times 10^{-8} \mathrm{mo} \mathrm{L}^{-1}, 1.8 \times 10^{-8} \mathrm{mo} \mathrm{L}^{-1}$, and $1.62 \times 10^{-9} \mathrm{mo} \mathrm{L}^{-1}$ (using $N$-benzoyl-DL-arginine- $p$-nitroaniline hydrochloride as substrate; Figure 3). The variants D67V and R68L were found to have only $1-2 \%$ of the FtTI activity. This indicated that the inhibitor contains at least one reactive site where the $\mathrm{P} 1$ residues $\mathrm{Asp}^{67}$ and $\mathrm{Arg}^{68}$ are capable of binding one molecule of trypsin. This discovery is consistent with previous results [33]. The electron densities of the P1 residues of the reactive site matched perfectly with those of residues $\mathrm{Asp}^{67}$ and $\mathrm{Arg}^{68}$, as reported previously $[4,10,32,33]$. We suggest that the fully functional recombinant $F t T I$ lost its trypsin inhibitory activity when its $\mathrm{Asp}^{67}$ or $\mathrm{Arg}^{68}$ residues were mutated. Of the P1-amino acid mutants studied, two amino acid residues in the site had essentially no trypsin inhibitory activities [10]. These had mutations at either $\mathrm{Asp}^{67}$ or $\mathrm{Arg}^{68}$, the negatively and positively charged residues, respectively, near 
the middle of the active site. The present work on FtTI further indicates that, even for the TI of this family, the inhibitory mechanism can also vary. Because of the presence of $\mathrm{P} 1$, neither residue Asp ${ }^{67}$ nor $\mathrm{Arg}^{68}$ at the reactive site of the D67V, R68L, and R68L/D67V mutants is favorable for trypsin binding; therefore, the mutants show quite weak inhibitory activity levels. The inhibitory activity of a protease inhibitor results from its ability to form a stable complex with the target protease, thereby blocking, altering, or preventing the substrate from entering the enzyme's active site $[8,34]$.
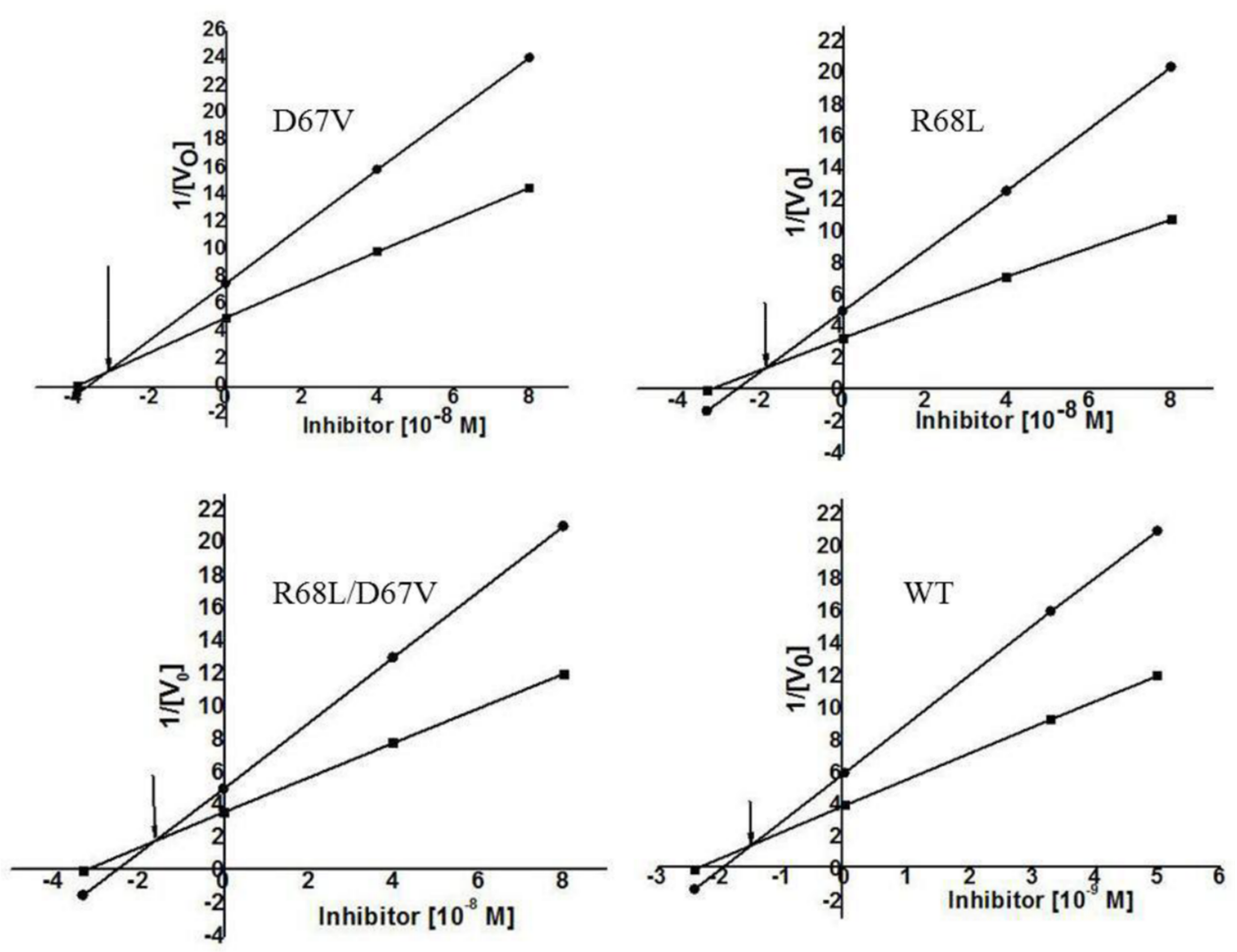

Figure 3. Kinetic analysis of the trypsin inhibitory activity of FtTI. Dixon plot for the determination of the dissociation constant (Ki) values of FtTI at two different concentrations of $N$ - $\alpha$-benzoyl-L-arginine ethyl ester hydrochloride. Final substrate concentrations were $0.01 \mathrm{M}(\boldsymbol{\square})$ and $0.005 \mathrm{M}(\mathbf{\Delta})$. The reciprocals of velocity were plotted against different concentrations of FtTI.

In summary, three FtTI mutants obtained by site-directed mutagenesis were used to investigate the structure-function relationship of the trypsin inhibitory activity. The study generated a series of results that appear to deviate from previous results related to how the P1 inhibitory active site of the potato protease inhibitor I family works and is stabilized. Most notably, our result indicated that the two amino acid residues in the FtTI P1 active site residues, Asp ${ }^{67}$ and Arg ${ }^{68}$, are critical for the inhibitory function, which conflicts with the long-held belief that only a positively charged amino acid is required. Our discovery thus suggests that trypsin inhibitory mechanisms are more complicated than previously thought, and should be the topic of renewed interest in further research on the potato protease inhibitor I family, especially its less well-known members.

\subsection{In-Vitro Antifungal Activity of Recombinant FtTI}

To determine whether the recombinant FtTI protein has a direct antifungal effect, it was purified from FtTI-expressing E. coli. The antifungal activity of the purified recombinant FtTI protein at various concentrations was tested against $A$. solani using a microtiter broth dilution assay. The purified recombinant FtTI protein completely inhibited $A$. solani mycelial growth at $50 \mu \mathrm{g} \mathrm{mL}^{-1}$ (Figure $4 \mathrm{~A}$ ). Fungal conidial germination was inhibited by recombinant thioredoxin-FtTI protein, but not by thioredoxin alone (Figure 4B). Treatment with $100 \mu \mathrm{g} \mathrm{mL}{ }^{-1}$ FtTI completely inhibited conidial 
germination (Figure 4B). At $1 \mu \mathrm{g} \mathrm{mL} \mathrm{m}^{-1}$, FtTI did not suppress A. solani spore germination. However, A. solani spore germination was strongly inhibited at 5 and $10 \mu \mathrm{gL}^{-1}$ FtTI. The hyphal growth of A. solani was completely inhibited at 50 and $100 \mu \mathrm{g} \mathrm{mL}^{-1}$ FtTI. These results indicate that the recombinant FtTI antifungal protein directly affects the mycelial growth and spore germination of fungal pathogens. Many plants respond to fungal attack by accumulating TI as a method of blocking fungal hyphal growth. TI production is one of the earliest cytological detectable responses to infection by fungal species. TIs also play vital roles in plant natural defenses against fungal infections. The function of FtTI in plant defense mechanisms has been extensively investigated, either in vivo using FtTI to fight plant-pathogenic microorganisms [24], or in vitro using native or recombinant FtTI to control lepidopteran pests [21,25]. In comparison with the recombinant FtTI, the inhibition of mycelial growth and spore germination by mutants D67V, R68L, and R68L/D67V decreased significantly, leading to a pronounced increase in the lengths of the mycelia and the numbers of conidia of A. solani (Figure 4). As shown by the arrows in Figure 5, compared with the control, the hyphal tips of the treatment group were deformed, the mycelial volumes were decreased, and no conidia were generated.

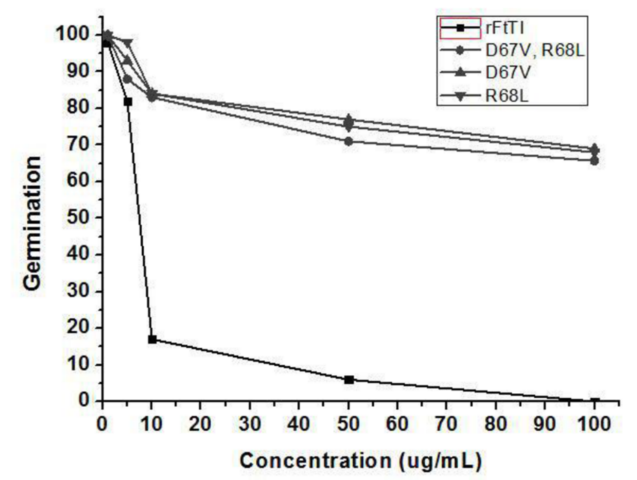

(A)

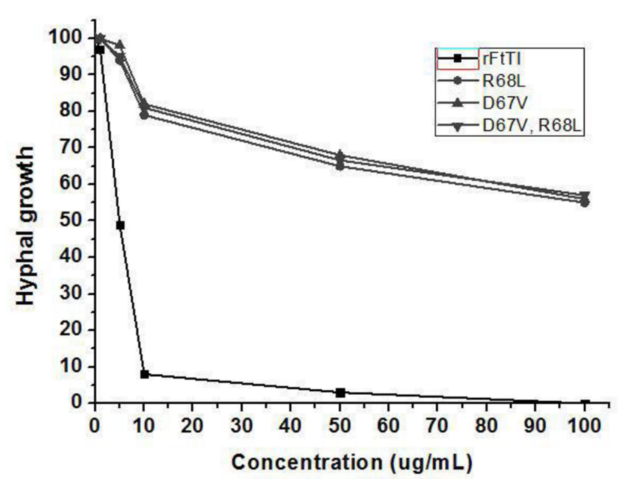

(B)

Figure 4. Inhibitory effects of the recombinant FtTI protein at various concentrations on the hyphal growth (A) and conidial germination (B) of A. solani. The results are expressed as relative values compared to those of untreated controls (set to $100 \%$ ).

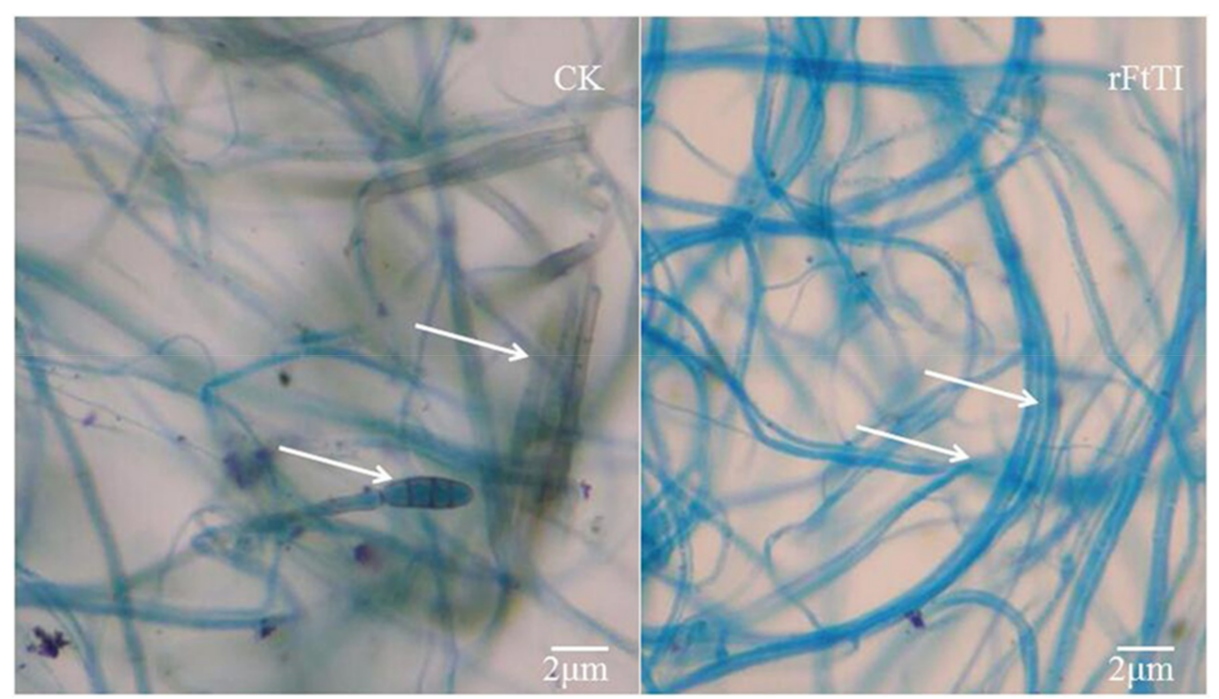

Figure 5. In vitro hyphal morphology studies. Left, hyphal morphology of Alternaria solani in a control well. Right, hyphal morphology of $A$. solani in a protein-treated well. Deformations of the hyphal tips (arrows) and decreases in mycelial volume compared to the control. 
Thus, we identified a novel anti-phytopathogen gene, FtTI, which was isolated from tartary buckwheat leaves infected with $A$. solani. The molecular inhibitory mechanism of FtTI against plant-pathogenic fungal spore germination and mycelial growth remains unknown. On the one hand, phytopathogenic fungi need to hydrolyze proteases during the process of infection and spread to obtain nutrients. On the other, weaker protease-inhibitor interactions might result in lower concentrations of the protease-inhibitor complexes that are perceived by FtTI, thus repressing plant-pathogenic fungal protease secretion upon spore germination and mycelial growth. The elucidation of the three-dimensional structures of FtTI in complex with proteases secreted by phytopathogenic fungi will help determine whether slight changes in the vital amino acids of the FtTI active site form the basis of mutual recognition by the protease-inhibitor complex. The blockage of phytopathogenic fungal signaling pathways and molecular mechanisms by plant protease inhibitors warrants further study.

\section{Conclusions}

Molecular cloning, expression, and site-mutation studies enabled the characterization of a TI from tartary buckwheat. Purified recombinant FtTI exhibited strong in vitro antifungal activities against $A$. solani phytopathogenic fungi. A multiple sequence alignment with related inhibitors and site-directed mutagenesis indicated that the $\mathrm{Asp}^{67}$ and $\mathrm{Arg}^{68}$ residues are essential for FtTI's inhibitory activity, as further substantiated by the mutational study of this TI.

Supplementary Materials: The following are available online at http:/ / www.mdpi.com/2073-4395/8/4/46/s1.

Acknowledgments: This research was financially supported by the Regional Funds of the National Natural Science Foundation of China (No. 31660531) and Guizhou University to Introduce Talent Research Projects (No. 2016040). We are very grateful Ming-jian Ren (Guizhou Sub-center of the National Wheat Improvement Center) for fruitful discussions on this work. We also acknowledge Prof. Guoshu Gong (Sichuan Agricultural University) and Lei Lei (Institute of Plant Protection of the Chinese Agricultural Academy of Sciences, Beijing, China) for anti-fungal tests.

Author Contributions: J.-j.R. and J.-p.C. designed research; J.-j.R., S.-j.T., H.C. and R.-h.X. performed research; H.C. contributed new reagents/analytic tools; H.C. and J.Y. analyzed data; and J.-j.R. and J.-p.C. wrote the paper.

Conflicts of Interest: The authors declare no conflict of interest.

\section{References}

1. Gaspar, Y.M.; McKenna, J.A.; McGinness, B.S.; Hinch, J.; Poon, S.; Connelly, A.A.; Anderson, M.A.; Heath, R.L. Field resistance to Fusarium oxysporum and Verticillium dahliae in transgenic cotton expressing the plant defensin NaD1. J. Exp. Bot. 2014, 65, 1541-1550. [CrossRef] [PubMed]

2. Tomazoni, E.Z.; Pauletti, G.F.; da Silva Ribeiro, R.T.; Moura, S.; Schwambach, J. In vitro and in vivo activity of essential oils extracted from Eucalyptus staigeriana, Eucalyptus globulus and Cinnamomum camphora against Alternaria solani Sorauer causing early blight in tomato. Sci. Hortic. 2017, 223, 72-77. [CrossRef]

3. Bathige, S.D.N.K.; Umasuthan, N.; Godahewa, G.I.; Jayasinghe, J.D.H.E.; Whang, I.; Noh, J.K.; Lee, J. A homolog of kunitz-type serine protease inhibitor from rock bream, oplegnathus fasciatus: Molecular insights and transcriptional modulation in response to microbial and pamp stimulation, and tissue injury. Fish Shellfish Immunol. 2015, 46, 285-291. [CrossRef] [PubMed]

4. Qi, R.F.; Liu, Z.X.; Xu, S.Q.; Zhang, L.; Shao, X.X.; Chi, C.W. Small peptides derived from the Lys active fragment of the mung bean trypsin inhibitor are fully active against trypsin. FEBS J. 2010, 277, $224-232$. [CrossRef] [PubMed]

5. Volpicella, M.; Leoni, C.; Arnesano, F.; Gallerani, R.; Ceci, L.R. Analysis by phage display selection and site-directed retromutagenesis of the Mustard Trypsin Inhibitor 2 reactive site. J. Plant Physiol. 2010, 167, 1507-1511. [CrossRef] [PubMed]

6. Ekchaweng, K.; Khunjan, U.; Churngchow, N. Molecular cloning and characterization of three novel subtilisin-like serine protease genes from Hevea brasiliensis. Physiol. Mol. Plant Pathol. 2017, 97, 79-95. [CrossRef] 
7. Liu, D.; Li, Y.; Man, L.; Wu, Q.; Liu, S.; Liu, Y. Molecular cloning and characterization of PtrZPT2-1, a ZPT2 family gene encoding a Cys2/His2-type zinc finger protein from trifoliate orange (Poncirus trifoliata, (L.) Raf.) that enhances plant tolerance to multiple abiotic stresses. Plant Sci. Int. J. Exp. Plant Biol. 2017, 263, 66-78. [CrossRef] [PubMed]

8. Shamsi, T.N.; Parveen, R.; Naz, H.; Haque, M.A.; Fatima, S. Biophysical insight into structure-function relation of Allium sativum Protease Inhibitor by thermal, chemical and $\mathrm{pH}$-induced modulation using comprehensive spectroscopic analysis. Int. J. Biol. Macromol. 2017, 103, 415-423. [CrossRef] [PubMed]

9. Júnior, J.E.M.; Valadares, N.F.; Pereira, H.D.; Dyszy, F.H.; da Costa Filho, A.J.; Uchôa, A.F.; de Oliveira, A.S.; da Silveira Carvalho, C.P.; Grangeiro, T.B. Expression in Escherichia coli of cysteine protease inhibitors from cowpea (Vigna unguiculata): The crystal structure of a single-domain cystatin gives insights on its thermal and pH stability. Int. J. Biol. Macromol. 2017, 102, 29-41. [CrossRef] [PubMed]

10. Yao, P.L.; Hwang, M.J.; Chen, Y.M.; Yeh, K.W. Site-directed mutagenesis evidence for a negatively charged trypsin inhibitory loop in sweet potato sporamin. FEBS Lett. 2001, 496, 134-138. [CrossRef]

11. Yu, Q.; Ryan, E.M.; Allen, T.M.; Birren, B.W.; Henn, M.R.; Lennon, N.J. PriSM: A primer selection and matching tool for amplification and sequencing of viral genomes. Bioinformatics 2011, 27, 266-267. [CrossRef] [PubMed]

12. Boyce, R.; Chilana, P.; Rose, T.M. iCODEHOP: A new interactive program for designing COnsensus-DEgenerate Hybrid Oligonucleotide Primers from multiply aligned protein sequences. Nucleic Acids Res. 2009, 37, $222-228$. [CrossRef] [PubMed]

13. René, O.; Alix, J.H. Late steps of ribosome assembly in E. coli are sensitive to a severe heat stress but are assisted by the HSP70 chaperone machine. Nucleic Acids Res. 2011, 39, 1855-1867. [CrossRef] [PubMed]

14. Brand, G.D.; Pires, D.A.T.; Furtado, J.R.; Cooper, A.; Freitas, S.M.; Bloch, C., Jr. Oligomerization affects the kinetics and thermodynamics of the interaction of a Bowman-Birk inhibitor with proteases. Arch. Biochem. Biophys. 2017, 618, 9-14. [CrossRef] [PubMed]

15. Gorrón, E.; Rodríguez, F.; Bernal, D.; Rodriguez-Rojas, L.M.; Bernal, A.; Restrepo, S.; Tohme, J. A new method for designing degenerate primers and its use in the identification of sequences in Brachiaria showing similarity to apomixis-associated genes. Bioinformatics 2010, 26, 2053-2054. [CrossRef] [PubMed]

16. Evans, B.A.; Hamouda, A.; Towner, K.J.; Amyes, S.G. Novel genetic context of multiple bla OXA-58 genes in Acinetobacter genospecies 3. J. Antimicrob. Chemother. 2010, 65, 1586-1588. [CrossRef] [PubMed]

17. Zhu, F. Chemical composition and health effects of Tartary buckwheat. Food Chem. 2016, 203, $231-245$. [CrossRef] [PubMed]

18. Bai, C.Z.; Feng, M.L.; Hao, X.L.; Zhao, Z.J.; Li, Y.Y.; Wang, Z.H. Anti-tumoral effects of a trypsin inhibitor derived from buckwheat in vitro and in vivo. Mol. Med. Rep. 2015, 12, 1777-1782. [CrossRef] [PubMed]

19. Khadeeva, N.V.; Kochieva, E.Z.; Tcherednitchenko, M.Y.; Yakovleva, E.Y.; Sydoruk, K.V.; Bogush, V.G.; Dunaevsky, Y.E.; Belozersky, M.A. Use of buckwheat seed protease inhibitor gene for improvement of tobacco and potato plant resistance to biotic stress. Biochemistry (Mosc.) 2009, 74, 260-267. [CrossRef] [PubMed]

20. Park, S.S.; Ohba, H. Suppressive activity of protease inhibitors from buckwheat seeds against human T-acute lymphoblastic leukemia cell lines. Appl. Biochem. Biotechnol. 2004, 117, 65-74. [CrossRef]

21. Wang, Z.; Li, S.; Ren, R.; Li, J.; Cui, X. Recombinant buckwheat trypsin inhibitor induces mitophagy by directly targeting mitochondria and causes mitochondrial dysfunction in Hep G2 cells. J. Agric. Food Chem. 2015, 63, 7795-7804. [CrossRef] [PubMed]

22. Ashouri, S.; Abad, R.F.P.; Zihnioglu, F.; Kocadag, E. Extraction and purification of protease inhibitor (s) from seeds of Helianthus annuus with effects on Leptinotarsa decemlineata digestive cysteine protease. Biocatal. Agric. Biotechnol. 2017, 9, 113-119. [CrossRef]

23. Qian, C.; Liang, D.; Liu, Y.; Wang, P.; Kausar, S.; Wei, G.; Zhu, B.; Wang, L.; Liu, C. Identification of a small pacifastin protease inhibitor from Nasonia vitripennis venom that inhibits humoral immunity of host (Musca domestica). Toxicon 2017, 131, 54-62. [CrossRef] [PubMed]

24. Ruan, J.J.; Chen, H.; Shao, J.R.; Wu, Q.; Han, X.Y. An antifungal peptide from Fagopyrum tataricum seeds. Peptides 2011, 32, 1151-1158. [CrossRef] [PubMed]

25. Ruan, J.; Yan, J.; Hou, S.; Chen, H.; Wu, Q.; Han, X. Expression and purification of the trypsin inhibitor from tartary buckwheat in Pichia pastoris and its novel toxic effect on Mamestra brassicae larvae. Mol. Biol. Rep. 2015, 42, 209-216. [CrossRef] [PubMed] 
26. Bhattacharjee, N.; Banerjee, S.; Dutta, S.K. Cloning, expression and mutational studies of a trypsin inhibitor that retains activity even after cyanogen bromide digestion. Protein Expr. Purif. 2014, 96, 26-31. [CrossRef] [PubMed]

27. Lee, H.; Ren, J.; Nocadello, S.; Rice, A.J.; Ojeda, I.; Light, S.; Minasov, G.; Vargas, J.; Nagarathnam, D.; Anderson, W.F.; et al. Identification of novel small molecule inhibitors against NS2B/NS3 serine protease from Zika virus. Antivir. Res. 2017, 139, 49-58. [CrossRef] [PubMed]

28. Wang, C.; Zhang, H.; Li, M.; Hu, X.Q.; Li, Y. Functional analysis of truncated and site-directed mutagenesis dextransucrases to produce different type dextrans. Enzyme Microb. Technol. 2017, 102, 26-34. [CrossRef] [PubMed]

29. Laemmli, U.K. Cleavage of structural proteins during the assembly of the head of bacteriophage T4. Nature 1970, 227, 680-685. [CrossRef] [PubMed]

30. Matsudaira, P. Sequence from picomole quantities of proteins electroblotted onto polyvinylidene difluoride membranes. J. Biol. Chem. 1987, 262, 10035-10038. [PubMed]

31. Lee, S.C.; Hwang, I.S.; Choi, H.W.; Hwang, B.K. Involvement of the pepper antimicrobial protein CaAMP1 gene in broad spectrum disease resistance. Plant Physiol. 2008, 148, 1004-1020. [CrossRef] [PubMed]

32. Gibaud, A.; Vogt, N.; Brison, O.; Debatisse, M.; Malfoy, B. Characterization at nucleotide resolution of the homogeneously staining region sites of insertion in two cancer cell lines. Nucleic Acids Res. 2013, 41, 8210-8219. [CrossRef] [PubMed]

33. Ambadapadi, S.; Zheng, D.; Munaswamy-Ramanujam, G.; Lucas, A. Serine protease inhibitor (serpin) reactive center loop peptides as therapy for inflammatory vasculitis, hemorrhage and acute viral sepsis. Atherosclerosis 2015, 241, e209. [CrossRef]

34. Bao, R.; Zhou, C.Z.; Jiang, C.; Lin, S.X.; Chi, C.W.; Chen, Y. The ternary structure of the double-headed arrowhead protease inhibitor API-A complexed with two trypsins reveals a novel reactive site conformation. J. Biol. Chem. 2009, 284, 26676-26684. [CrossRef] [PubMed]

(C) 2018 by the authors. Licensee MDPI, Basel, Switzerland. This article is an open access article distributed under the terms and conditions of the Creative Commons Attribution (CC BY) license (http:/ / creativecommons.org/licenses/by/4.0/). 